\title{
Notch signaling promotes a HIF2a-driven hypoxic response in multiple tumor cell types
}

\author{
Anders P. Mutvei ${ }^{1}$ - Sebastian K.-J. Landor ${ }^{1,2}$ - Rhys Fox ${ }^{1}$ Eike-Benjamin Braune ${ }^{1}$ - Yat Long Tsoi ${ }^{1}$. \\ Yee Peng Phoon ${ }^{1}$. Cecilia Sahlgren ${ }^{2} \cdot$ Johan Hartman $\mathbb{B}^{3} \cdot$ Jonas Bergh $^{4,5} \cdot{\text { Shaobo } \text { Jin }^{1} \cdot \text { Urban Lendahl }}^{1}$
}

Received: 15 August 2017 / Revised: 7 May 2018 / Accepted: 12 June 2018 / Published online: 11 July 2018

(c) The Author(s) 2018. This article is published with open access

\begin{abstract}
Hyperactivation of Notch signaling and the cellular hypoxic response are frequently observed in cancers, with increasing reports of connections to tumor initiation and progression. The two signaling mechanisms are known to intersect, but while it is well established that hypoxia regulates Notch signaling, less is known about whether Notch can regulate the cellular hypoxic response. We now report that Notch signaling specifically controls expression of HIF2 $\alpha$, a key mediator of the cellular hypoxic response. Transcriptional upregulation of HIF $2 \alpha$ by Notch under normoxic conditions leads to elevated HIF $2 \alpha$ protein levels in primary breast cancer cells as well as in human breast cancer, medulloblastoma, and renal cell carcinoma cell lines. The elevated level of HIF $2 \alpha$ protein was in certain tumor cell types accompanied by downregulation of HIF1 $\alpha$ protein levels, indicating that high Notch signaling may drive a HIF1 $\alpha$-to-HIF2 $\alpha$ switch. At the transcriptome level, the presence of HIF $2 \alpha$ was required for approximately $21 \%$ of all Notch-induced genes: among the 1062 genes that were upregulated by Notch in medulloblastoma cells during normoxia, upregulation was abrogated in 227 genes when HIF $2 \alpha$ expression was knocked down by HIF2 $\alpha$ siRNA. In conclusion, our data show that Notch signaling affects the hypoxic response via regulation of $\mathrm{HIF} 2 \alpha$, which may be important for future cancer therapies.
\end{abstract}

Electronic supplementary material The online version of this article (https://doi.org/10.1038/s41388-018-0400-3) contains supplementary material, which is available to authorized users.

Shaobo Jin

Shaobo.Jin@ki.se

$\triangle$ Urban Lendahl

Urban.Lendahl@ki.se

1 Department of Cell and Molecular Biology, Karolinska Institutet, Stockholm, Sweden

2 Turku Centre for Biotechnology, University of Turku and Åbo Akademi University, 20520 Turku, Finland

3 Department of Oncology-Pathology, Karolinska Institutet, Stockholm, Sweden

4 Department of Oncology-Pathology, Karolinska Institutet, Radiumhemmet, Breast Cancer, Cancer Theme, Karolinska University Hospital, Stockholm, Sweden

5 Present address: Department of Public Health, Oxford University, Oxford OX1 2JD, UK

\section{Introduction}

Interaction between signaling pathways is vital during normal development and tissue homeostasis. Dysregulation of signaling pathways is also increasingly linked to cancer and a downside of pathway integration is that dysregulation of a particular pathway in a tumor situation may also influence signaling from other interacting pathways, further aggravating disease. An improved understanding of how signaling pathways interact is therefore warranted, as it may facilitate tailored therapy approaches based on identified pathway abnormalities.

In this study, we addressed whether the Notch singling pathway modulates the cellular response to hypoxia, i.e., low oxygen conditions. The Notch signaling pathway is a highly evolutionarily conserved cell-cell contact-dependent signaling mechanism, which is activated when a ligand binds to a Notch receptor, leading to receptor cleavage and the release of the Notch intracellular domain (Notch ICD). Notch ICD subsequently translocates to the nucleus and forms a ternary transcriptional activation complex with CSL (also known as RBP-Jk) and Mastermind-like (MAML) to induce expression of downstream target 
genes, including Notch-regulated ankyrin repeat-containing protein (NRARP), Hes, or Hey genes $[1,2]$. Notch mutations are found in several tumor types, having either oncogenic or tumor suppressor roles, depending on the type of tumor [3].

In order to adapt their physiological responses to different oxygen levels, cells are endowed with a specific signaling system: the cellular hypoxic response. Central to the cellular hypoxic response are the two oxygen-labile transcription factors: Hypoxia-inducible factor (HIF) $1 \alpha$ and $2 \alpha$ (collectively referred to as HIF $\alpha$ ). In normoxia, HIF $\alpha$ is hydroxylated by oxygen-sensing prolyl hydroxylase proteins, leading to ubiquitylation by the E3 ubiquitin ligase Von Hippel-Lindau (VHL) and subsequent proteasomal degradation. Under hypoxic conditions, the prolyl hydroxylases are inactivated, resulting in stabilization of $\mathrm{HIF} \alpha$, which bind to the constitutively expressed HIF $1 \beta$ and activate downstream target genes [4]. Although HIF1 $\alpha$ and HIF $2 \alpha$ are structurally quite similar [5], they exert at least partly different functions by activating genes specific to each paralog [6-10] (for review see [11]); for example, HIF1 $\alpha$ controls genes involved in glycolysis, whereas HIF2 $\alpha$ regulates matrix metalloproteases important for cellular motility and invasion [6, 8,12-14]. HIF $1 \alpha$ and HIF $2 \alpha$ also exhibit different temporal patterns upon a hypoxic onset in certain contexts. In neuroblastoma, HIF $1 \alpha$ is stabilized rapidly in response to hypoxia, mediating the acute cellular response to oxygen deprivation, whereas HIF $2 \alpha$ accumulates later and mediates the chronic effects of hypoxia $[15,16]$. The transition from HIF1 $\alpha$ to HIF $2 \alpha$ is referred to as the HIF1 $\alpha$-to-HIF2 $\alpha$ switch [17], but the molecular basis for this transition remains poorly understood. Hypoxia signaling components are frequently mutated in cancers. Abnormal HIF $2 \alpha$ stabilization, through HIF $2 \alpha$ gain-of-function or VHL loss-of-function mutations [17], has been found in pheochromocytomas and paragangliomas [18-20], as well as loss of VHL in clear cell renal carcinoma (for review see [21, 22]). Furthermore, hypoxic tumors promote resistance to chemotherapy and radiation treatment (for review, see [23]).

Upon hypoxia, Notch signaling activity is increased through multiple mechanisms [24]. HIF1 $\alpha$ directly binds to and stabilizes Notch ICD [25, 26] during hypoxia, leading to enhanced activation of Notch downstream genes [2731]. Hypoxia also induces expression of Notch ligands, such as Jagged 2 and Delta-like Ligand 4 (Dll4) [32-35]. In contrast, whether Notch signaling influences the cellular hypoxic response remains less explored [36-38]. Here, we report that Notch signaling regulates the hypoxic response in multiple tumor types by controlling HIF $2 \alpha$ expression. In addition, we provide evidence that a significant portion of the Notch-induced transcriptome requires functional HIF $2 \alpha$.

\section{Results}

\section{Notch signaling upregulates HIF2a mRNA levels in various types of cancer cells}

To learn whether Notch signaling affects the cellular hypoxic response, we searched published Notchtranscriptomes for alterations in expression of genes involved in the hypoxic response. In several transcriptomes, we noted that HIF2 $\alpha$ mRNA expression levels were increased during conditions where Notch signaling was activated and, conversely, decreased under conditions of Notch blockage (Fig. 1a). To test whether Notch regulates HIF2 $\alpha$ mRNA expression, we expressed an activated form of Notch (Notch1 ICD) (Supplementary Figure 1A) in nine different human tumor cell lines derived from a range of tumors (renal, breast, lung, brain, and blood cancer cells), and monitored HIF $1 \alpha$ and HIF $2 \alpha$ mRNA levels in normoxia (21\% oxygen). HIF2 $\alpha$ mRNA levels were significantly upregulated by Notch activation in eight of the nine cell lines in normoxia (Fig. 1b). In contrast, expression of HIF1 $\alpha$ remained unchanged in all cell lines except for in the estrogen receptor-positive cell line MCF7 (Fig. 1b). As a control for Notch activation, expression levels of the canonical Notch target genes NRARP, Hes1, and Hey1 [39] were shown to be upregulated in all cell lines (Supplementary Figure 1B). To learn whether a more physiological mode of Notch activation can induce HIF $2 \alpha$ expression, we cultured MDA-MB-231 cells on immobilized Jagged1 or Dl14 ligands in normoxia. Ligand stimulation in both cases gave rise to a robust activation of HIF $2 \alpha$ mRNA expression, which was abrogated by the $\gamma$-secretase inhibitor 5difluorophenylacetyl-L-alanyl-2-phenylglycine-1,1-dimethylethyl ester (DAPT) (Fig. 1c). Thus, HIF2 $\alpha$ activation can be induced by Notch signaling in a process requiring the release of the Notch ICD.

We next investigated if Notch signaling controls HIF2 $\alpha$ also in cells from primary human cancers. Primary breast cancer and glioblastoma cells robustly upregulated HIF2 $\alpha$ mRNA expression upon Notch activation in normoxia, using Jagged1 ligand stimulation or expression of Notch1 and 2 ICD (Fig. 1d, e). In addition, Notch-activated HIF $2 \alpha$ mRNA also in non-tumorigenic primary mesenchymal cells (Fig. 1f). Taken together, these data demonstrate that elevated Notch signaling induces HIF $2 \alpha$ mRNA expression in several established cell lines and primary tumor cells in normoxia.

To explore whether a similar relationship between Notch and HIF2 $\alpha$ was observed also under hypoxia, we monitored mRNA levels of HIF1 $\alpha$, HIF2 $\alpha$, and NRARP in MDA-MB231 cells cultured on immobilized ligands for 24 , 48 , or $72 \mathrm{~h}$ in normoxia or hypoxia. To avoid potential pericellular hypoxia from high cellular confluence, sparse seeding was 
A

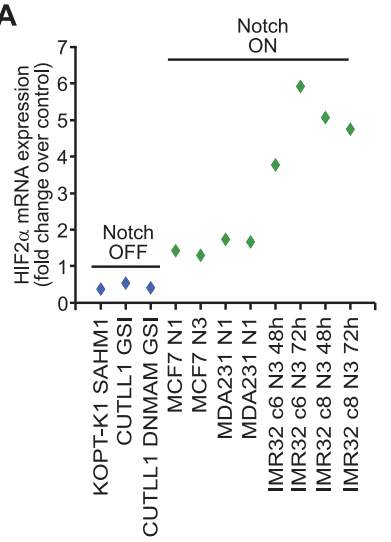

C

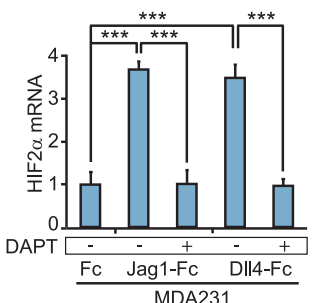

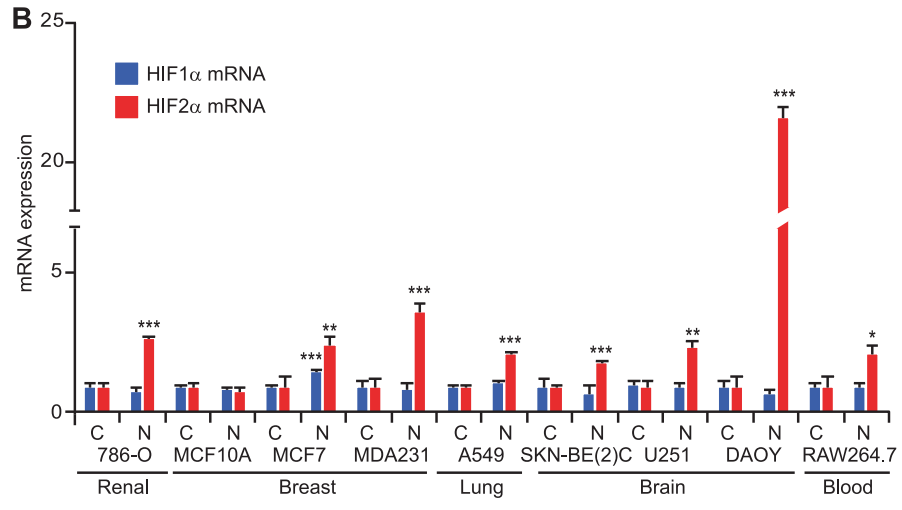

D

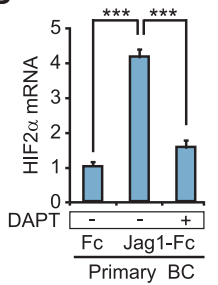

E

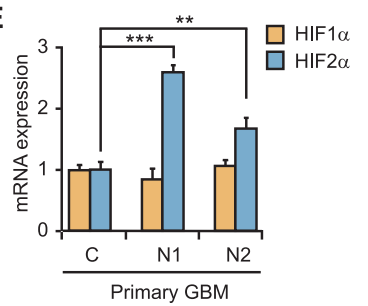

$\mathbf{F}$

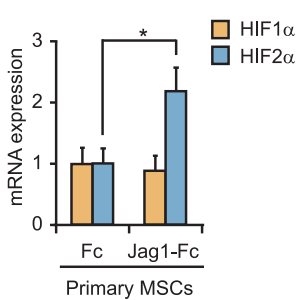

G
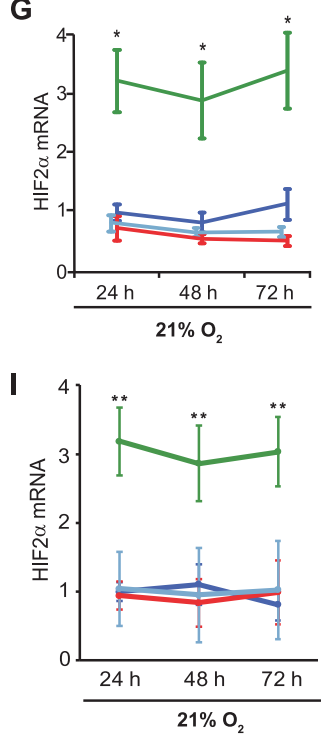

K
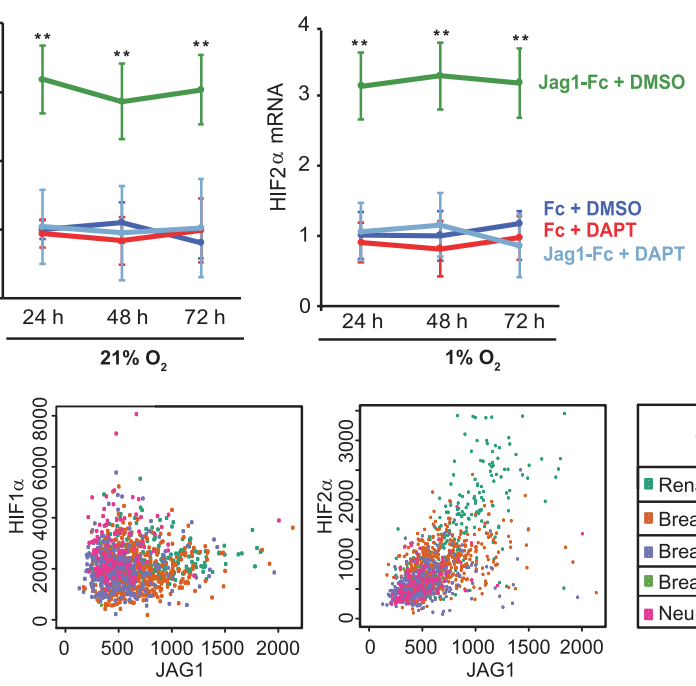

H
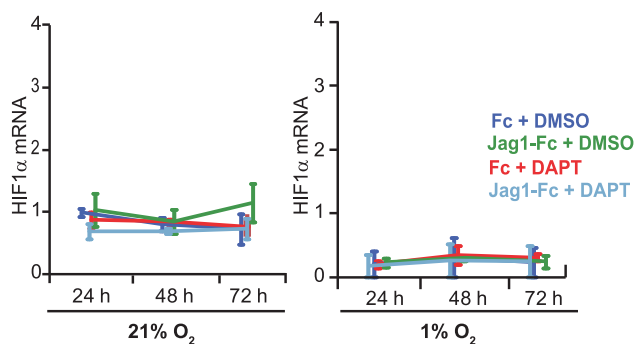

$\mathbf{J}$
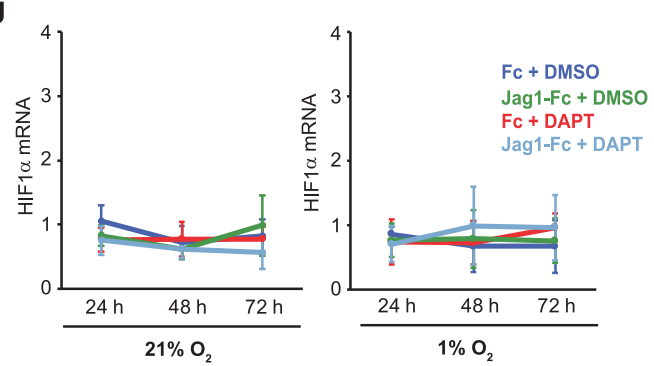

\begin{tabular}{|l|c|c|c|c|}
\hline \multirow{2}{*}{ Correlation JAG1 VS: } & \multicolumn{2}{|c|}{ HIF1 $\alpha$} & \multicolumn{2}{c|}{ HIF2 $\alpha$} \\
\cline { 2 - 5 } & $\mathrm{r}$ & $\mathrm{p}$ & $\mathrm{r}$ & $\mathrm{p}$ \\
\hline Renal cancer, $\mathrm{n}=\mathbf{2 0 9}$ & -0.031 & 0.66 & 0.65 & $<2.2 \mathrm{e}-16$ \\
\hline Breast carcinoma, NOS, $\mathrm{n}=553$ & 0.062 & 0.14 & 0.43 & $<2.2 \mathrm{e}-16$ \\
\hline Breast ductal cancer, $\mathrm{n}=327$ & 0.040 & 0.47 & 0.39 & $1.8 \mathrm{e}-13$ \\
\hline Breast cancer, others, $\mathrm{n}=15$ & 0.038 & 0.90 & 0.64 & 0.01 \\
\hline E Neuroblastoma, $\mathrm{n}=123$ & 0.127 & 0.16 & 0.50 & $4.0 \mathrm{e}-09$ \\
\hline
\end{tabular}

used for later time points (Supplementary Figure 1C). HIF2 $\alpha$ and NRARP mRNA expression was upregulated already after $24 \mathrm{~h}$ of Notch signaling activation, and remained significantly elevated at all time points under both hypoxic and normoxic conditions (Fig. 1g and Supplementary Figure 1D). The elevated levels of HIF2 $\alpha$ and
NRARP expression by Notch were dependent on Notch receptor cleavage, as the upregulation was abrogated by DAPT treatment (Fig. 1g and Supplementary Figure 1D). In contrast, HIF1 $\alpha$ mRNA levels were not altered by changes in Notch signaling, but were decreased by hypoxia at all time points analyzed (Fig. 1h). An equivalent robust 
Fig. 1 Notch signaling activates HIF $2 \alpha$ expression. a HIF $2 \alpha$ expression levels in publicly available transcriptome data sets where Notch signaling had been blocked (=Notch OFF) by the use of $\gamma$-secretase inhibitors (GSI), a dominant negative version of MAML1 (DNMAM) or by a stapled Maml1 peptide (SAHM1), or activated (=Notch ON) by Notch 1 or Notch 3 ICD (N1 and N3, respectively). b HIF1 $\alpha$ and HIF $2 \alpha$ mRNA expression measured by quantitative PCR (qPCR) in nine cell lines infected with adenoviral vectors expressing GFP (C; control) or Notch1 ICD (N) for $24 \mathrm{~h}$ at normoxia (see Supplementary Figure 1A for Notch1 ICD expression levels). c, d HIF2 $\alpha$ mRNA expression levels measured by qPCR in MDA-MB-231 breast cancer cells (c) or primary breast cancer cells (d), cultured for $24 \mathrm{~h}$ at normoxia on immobilized Jagged1 (Jag1-Fc) or Dll4 ligands (Dll4-Fc), or $\mathrm{Fc}$ fragments as control, in combination with the $\gamma$-secretase inhibitor DAPT, as indicated. e, f HIF $1 \alpha$ and HIF $2 \alpha$ mRNA expression in primary glioblastoma (GBM) cells (e) or primary mesenchymal cells (MSCs) (f) after $24 \mathrm{~h}$ of Notch activation by adenovirus-mediated expression of Notch1 ICD (N1) or Notch2 ICD (N2), (e) or by immobilized Jagged1 ligand (f). (G-J) $\operatorname{HIF} 2 \alpha(\mathbf{G}, \mathbf{I})$ and $\operatorname{HIF} 1 \alpha(\mathbf{H}, \mathbf{J})$ mRNA expression measured by qPCR in MDA-MB-231 $(\mathbf{g}, \mathbf{h})$ or primary breast cancer cells $(\mathbf{i}, \mathbf{j})$, cultured at normoxia $\left(21 \% \mathrm{O}_{2}\right)$ or hypoxia $\left(1 \% \mathrm{O}_{2}\right)$ for 24,48 , and $72 \mathrm{~h}$, on immobilized Jagged1 (Jag1$\mathrm{Fc}$ ) ligands, or $\mathrm{Fc}$ fragments as control, in combination with DMSO or DAPT, as indicated. (K) Correlation between Jagged1 (JAG1) and HIF $1 \alpha$ or HIF $2 \alpha$ mRNA expression levels in transcriptome data sets from the GeneSapiens data base. $r=$ correlation coefficient. $p=p$ value. Values are significant at $* * * p<0.001, * * p<0.01$, and $* p<$ 0.05 . Graphs represent an average of at least three independent experiments

upregulation of HIF $2 \alpha$, but not of $\mathrm{HIF} 1 \alpha$, was observed in primary breast cancer cells (Fig. 1i, j).

Given that Notch controls HIF $2 \alpha$ expression in multiple tumor cell types, we investigated whether the level of Notch signaling correlated with HIF $2 \alpha$ expression levels across primary cancers, using transcriptome data from multiple tumors of renal, breast, neuroblastoma, and medulloblastoma origin [40]. Since Notch downstream target genes are known to vary in a cell context-dependent manner [1, 41], we utilized Jagged1 expression as a proxy for active Notch signaling, in keeping with previous studies [42, 43]. HIF $2 \alpha$ and Jagged 1 expression correlated significantly in all tumor types analyzed (renal cancer, $n=209, R^{2}=0.65, p<$ $2.2 * 10^{-16}$; breast carcinoma, not otherwise specified (NOS), $n=553, R^{2}=0.43, p<2.2 * 10^{-16}$; ductal breast cancer, $n=327, R^{2}=0.39, p<1.8 * 10^{-13}$, breast cancer, others, $n=15, R^{2}=0.64, p<0.01$; neuroblastoma, $n=123$, $R^{2}=0.50, p<4.0 * 10^{-9}$; medulloblastoma, $n=62, R^{2}=$ $0.36, p=0.0043$; Fig. 1k, Supplementary Figure 1E). In contrast, HIF1 $\alpha$ and Jagged1 expression levels did not correlate significantly in any of the tumors (renal cancer; $R^{2}$ $=-0.031, p=0.66$; breast carcinoma, NOS, $R^{2}=0.062, p$ $=0.14$; breast ductal cancer, $R^{2}=0.040, p=0.47$; breast cancer, others, $R^{2}=0.038, p=0.90$; neuroblastoma, $R^{2}=$ 0.127, $p=0.16$; medulloblastoma, $R^{2}=0.04, p=0.73$; Fig. $1 \mathrm{k}$, Supplementary Figure $1 \mathrm{E}$ ). In sum, these data show that Notch signaling regulates HIF $2 \alpha$ mRNA levels in a variety of cancers.

\section{HIF2a mRNA expression is regulated by canonical Notch signaling but not through direct transcriptional activation via the HIF2a proximal promoter}

Canonical Notch signaling is executed via the ternary Notch ICD/MAML1/CSL complex acting on the promoter of a downstream gene, yet various forms of non-canonical signaling exist, some of which bypass the need for nuclear localization of Notch [44]. To learn whether nuclear localization of Notch1 ICD is required for HIF2 $\alpha$ activation, we transiently expressed a Notch1 ICD-estrogen receptor fusion construct (NERT2), which relocates from the cytoplasm to the nucleus upon addition of tamoxifen [42, 45, 46] (Fig. 2a). In medulloblastoma DAOY cells, as well as in MCF7 cells, expression of cytoplasmic NERT2 did not enhance HIF $2 \alpha$ or NRARP expression, whereas tamoxifeninduced nuclear localization of NERT2 for $8 \mathrm{~h}$ led to a robust upregulation of HIF $2 \alpha$ and NRARP expression (Fig. $2 \mathrm{~b}$, Supplementary Figure 2A). To test whether the canonical Notch transcriptional activation complex is required for HIF2 $\alpha$ upregulation, we introduced a truncated form of MAML1 (dnMAML) that blocks the interaction between Notch ICD and CSL [47]. Expression of dnMAML abrogated NERT2-mediated upregulation of both HIF2 $\alpha$ and NRARP expression following tamoxifen treatment (Fig. 2c, Supplementary Figure 2B), indicating that HIF2 $\alpha$ expression is controlled via canonical Notch signaling. In support of this notion, inactivation of the CSL gene by CRISPR/ Cas9 genome editing also blunted the upregulation of HIF $2 \alpha$ by Notch in DAOY cells (Fig. $2 d$ ).

To learn more about how Notch upregulates HIF $2 \alpha$, we investigated whether the canonical Notch transcriptional machinery binds directly to the HIF $2 \alpha$ promoter, or whether upregulation of HIF $2 \alpha$ occurs in a more indirect fashion. To test the first scenario, we conducted a chromatin immunoprecipitation sequencing (ChIP-seq) experiment to analyze potential binding of CSL to the HIF2 $\alpha$ (EPAS1) locus. No specific CSL occupancy was detected in the HIF $2 \alpha$ promoter or gene during Notch activation under which CSL binding to a well-established binding site in the HES1 promoter was detected (Fig. 2e). In keeping with this finding, Notch activation did not stimulate a HIF2 $\alpha$ promoter-luciferase reporter construct containing the -1000 to $+418 \mathrm{bp}$ region flanking the transcriptional start site (Fig. 2f). To explore if HIF2 $\alpha$ expression was regulated in a more indirect manner, we tested the effect of blocking protein translation by cycloheximide $(\mathrm{CHX})$ in conjunction with Notch activation. CHX treatment abrogated the Notch-dependent upregulation of HIF2 $\alpha$, whereas the upregulation of NRARP was unaffected by $\mathrm{CHX}$ (Fig. 2g, h), as expected. Blockage of transcription by actinomycin D treatment abrogated Notch activation of both HIF $2 \alpha$ and NRARP (Fig. 2i, j). Collectively, these data 
A

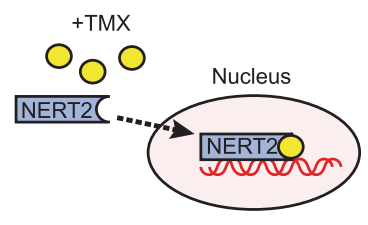

B

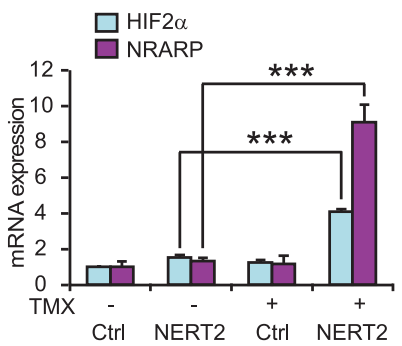

C

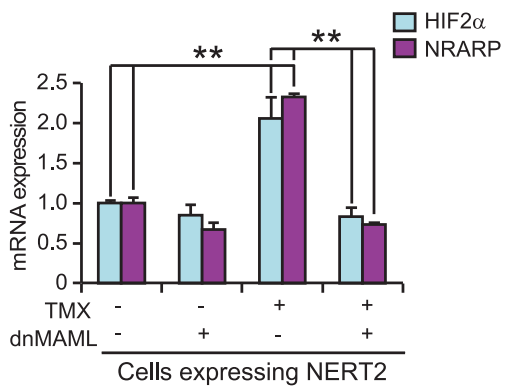

D

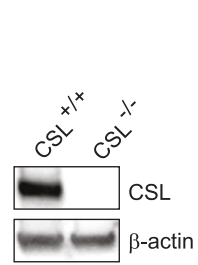

$\mathbf{F}$

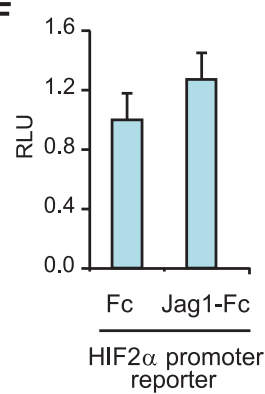
reporter

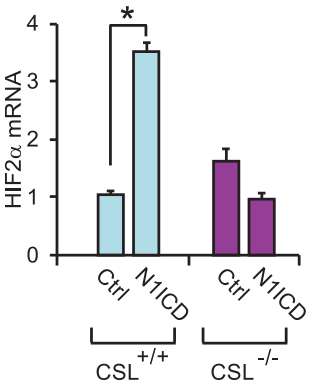

E

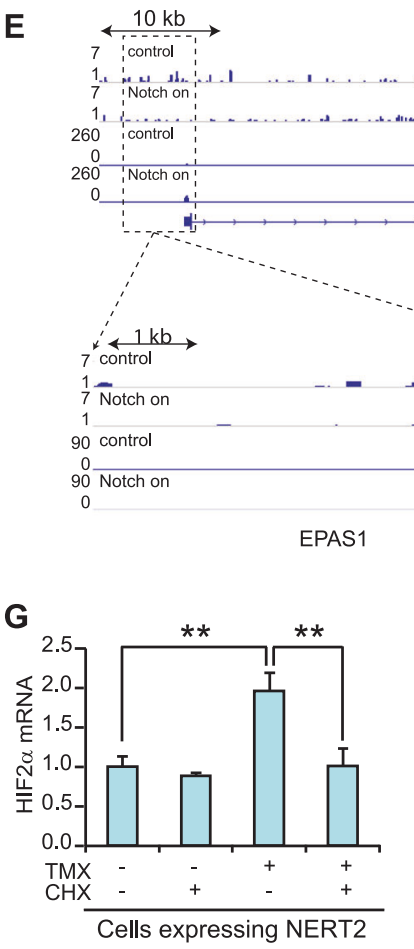

Fig. 2 HIF $2 \alpha$ expression is regulated by canonical Notch signaling, but not through direct transcriptional activation. a Schematic illustration of the NERT2 system where Notch1 ICD nuclear localization and thus Notch signaling is activated by addition of 4-OH tamoxifen (TMX). b, c HIF $2 \alpha$ and NRARP mRNA expression after Notch signaling activation by $50 \mathrm{nM}$ TMX in DAOY cells transiently (b) or stably (c) expressing NERT2, in combination with expression of dnMAML (c). d Western blot analysis of CSL levels in CRISPR/Cas9inactivated $\left(\mathrm{CSL}^{-/-}\right)$and control $\left(\mathrm{CSL}^{+/+}\right)$DAOY cells (left), and with HIF2 $\alpha$ mRNA expression upon Notch1 ICD expression in these cells (right). e Analysis of CSL binding to the promoters of HIF2 $\alpha$ (EPAS1; top and lower left) and HES1 (lower right) under control or Jagged1stimulating conditions (Notch on). No specific CSL binding was
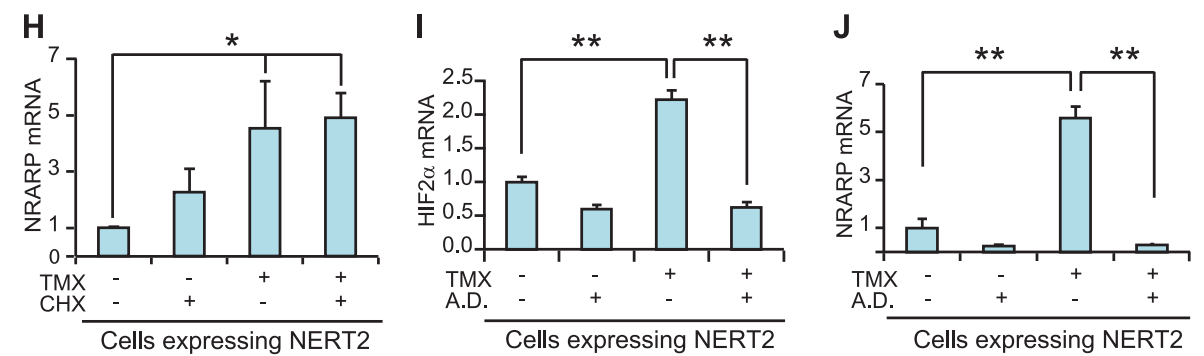

recorded in the HIF $2 \alpha$ promoter, whereas CSL binding to an established CSL-binding site located approximately $60 \mathrm{bp}$ of the HES1 transcription start site was recorded following Notch activation. f Analysis of a HIF $2 \alpha$ promoter-luciferase reporter construct upon cultivation of MDA-MB-231 cells on immobilized Jagged1 ligand (Jag1-Fc) or Fc fragments. g-j Analysis of HIF2 $\alpha$ (g, i) and NRARP $(\mathbf{h}, \mathbf{j})$ mRNA expression in DAOY cells transiently expressing NERT2 in combination with TMX treatment to activate Notch signaling. Cells were treated with $10 \mu \mathrm{g} / \mathrm{mL}$ cycloheximide (CHX) for $8 \mathrm{~h}$ to block translation $(\mathbf{g}, \mathbf{h})$ or $1 \mu \mathrm{g} / \mathrm{mL}$ actinomycin D (A.D.) for $8 \mathrm{~h}$ to block transcription (i, j). Values are significant at $* * * p<0.001, * * p<0.01$, and $* p<0.05$. Graphs represent an average of at least three independent experiments 
suggest that Notch ICD/CSL activates an intermediate protein controlling the HIF $2 \alpha$ upregulation, rather than binding to the HIF $2 \alpha$ promoter. Of note, actinomycin D negatively regulated mRNA expression of NERT2 (Supplementary Figure 2C, D), but the strong induction of NRARP expression (Fig. 2b, c, h) argues that sufficient amounts of the NERT2 protein are "preloaded" in the cytoplasm prior to tamoxifen induction to execute a robust Notch activation. Induction by tamoxifen increased the expression of NERT2 mRNA (Supplementary Figure 2C, D), but the reason for this is not understood. We next tested the potential role of three candidate intermediate proteins in the Notch-activation of HIF2 $\alpha$ (Hes1, Hey1, and p53), which in other contexts have been shown to mediate Notch responses [42]. Overexpression of wild-type p53 (since p53 is mutated in MDA-MB-231 cells), Hes1 or Hey1, however, did not upregulate HIF $2 \alpha$ (Supplementary Figure $2 \mathrm{E}$ ). Collectively, these data suggest that HIF $2 \alpha$ is controlled by canonical Notch signaling in an indirect manner.

\section{Elevated Notch signaling enhances HIF2a protein levels and induces a HIF1a-to-HIF2a switch}

The HIF $\alpha$ proteins are degraded in normoxia, but given the magnitude of the HIF $2 \alpha$ mRNA induction by Notch, we reasoned that the increase in mRNA may result in increased HIF $2 \alpha$ protein levels also in normoxia. In line with this, ectopic Notch1 ICD expression, which results in high levels of Notch signaling activation, increased normoxic HIF2 $\alpha$ protein in primary breast cancer cells (Fig. 3a), human medulloblastoma cell lines D324 and DAOY (Fig. 3b, c), as well as the VHL-deficient 786-O renal carcinoma cell line (Fig. 3d). The ability of Notch to activate HIF $2 \alpha$ is conserved across the different Notch paralogs, as Notch2 and 3 ICDs also induced robust HIF2 $\alpha$ protein upregulation (Fig. $3 e)$. Ligand-mediated activation, which produces a more moderate Notch signaling activation, readily increased HIF $2 \alpha$ protein in normoxia in MDA-MB-231 after $24 \mathrm{~h}$, but not $72 \mathrm{~h}$, of activation (Fig. 3f), and did not elevate normoxic HIF $2 \alpha$ protein in primary breast cancer cells (Fig. $3 \mathrm{~g})$. However, if breast cancer cells were ligand-stimulated during hypoxia, increased HIF $2 \alpha$ protein levels were observed, both in primary breast cancer cells and MDAMB-231 cells (Fig. 3f, g). Elevated HIF2 $\alpha$ protein levels were also observed when D324 and DAOY cells were treated with $\mathrm{CoCl}_{2}$, a widely used hypoxia mimetic (Fig. 3b, c).

In several of the cell types, Notch activation also led to decreased HIF1 $\alpha$ protein levels: this was observed in D324
A

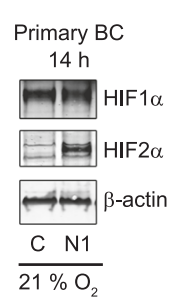

B

D324 (Medulloblastoma) $24 \mathrm{~h}$
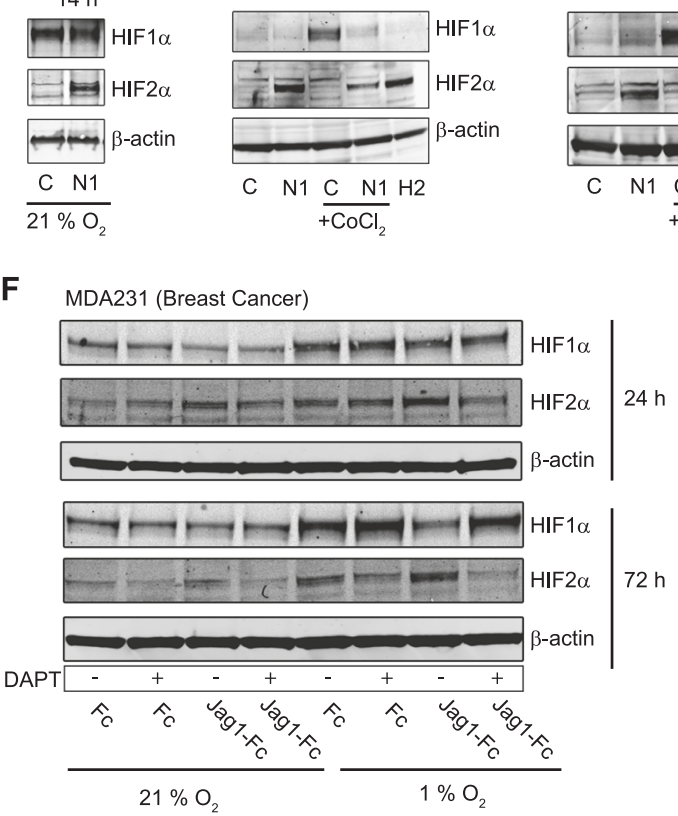

Fig. 3 Notch signaling increases HIF $2 \alpha$ protein expression and triggers a HIF1 $\alpha$-to-HIF2 $\alpha$ switch. a-g HIF1 $\alpha$ and HIF2 $\alpha$ protein levels measured by Western blotting in: (a, e, $\mathbf{g}$ ) primary breast cancer cells, (b) D324 medulloblastoma cells, (c) DAOY medulloblastoma cells, (d) 786-O renal carcinoma cells and (f) MDA-MB-231 cells, cultured on immobilized Jagged1 ligands in combination with DAPT treatment $(\mathbf{f}, \mathbf{g})$ or upon adenovirus-mediated expression of GFP (c), Notch1 ICD

G
D

E

786-O (Renal carcinoma) $24 \mathrm{~h}$
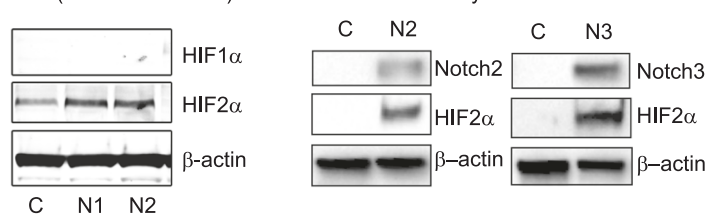

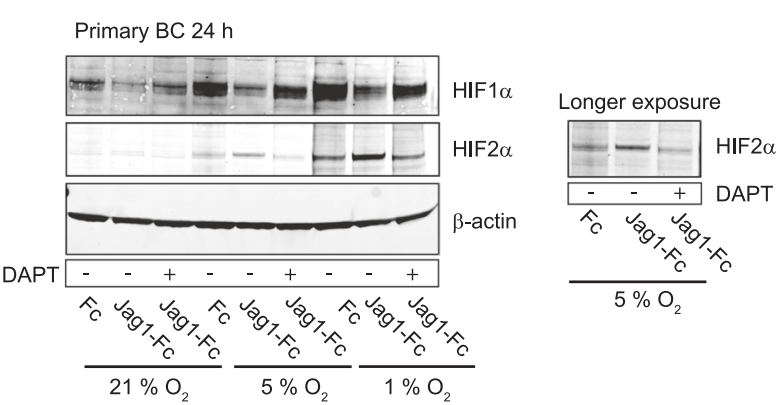

(N1), Notch2 ICD (N2), or Notch3 ICD (N3) (b, c, d, e), as indicated. In (b) and (c), cells were treated with cobalt (II) chloride $\left(\mathrm{CoCl}_{2}\right)$ as a hypoxia mimetic and in (f) and (g), cells were cultured in 21,5 , or $1 \%$ oxygen, as indicated. b $\mathrm{H} 2=$ transient expression of HIF $2 \alpha$ from an exogenous promoter as positive control. All experiments were repeated at least three times 
cells (Fig. 3b) and primary breast cancer both at normoxia and hypoxia (Fig. 3g), as well as in the MDA-MB-231 cells after $72 \mathrm{~h}$ in hypoxia (Fig. 3f). The fact that HIF1 $\alpha$ downregulation was observed in the primary breast cancer cells after 24 h (Fig. 3g), but not after 14 h (Fig. 3a) may indicate that it takes a certain time period to achieve this downregulation and execute the HIF1 $\alpha$-to-HIF $2 \alpha$ switch. A number of proteins have been implicated in controlling the HIF1 $\alpha$-to-HIF $2 \alpha$ switch, including HAF [17], HSP70, and CHIP [48]. While HAF and HSP70 were not regulated by Notch1 ICD (data not shown), we found that CHIP, which encodes a ubiquitin ligase involved in HIF1a degradation [48], was moderately upregulated by Jagged 1 immobilized ligand stimulation and strongly reduced by DAPT (Supplementary Figure 3A), making it a candidate mediator between Notch and HIF1 $\alpha$ regulation.

\section{A subset of the Notch-induced transcriptome depends on the presence of HIF2a}

Given that HIF2 $\alpha$ is a transcription factor, a potential consequence of our findings is that a Notch-induced transcriptome may consist of genes that are activated by both Notch ICD and HIF2 $\alpha$. To learn whether HIF $2 \alpha$-specific genes are induced during Notch activation, we first tested whether Notch increased expression of two genes, VEGF and AREG, which are regulated by hypoxia and HIF2 $\alpha$, respectively $[49,50]$. Both VEGF and AREG were upregulated by Notch in MDA-MB-231 cells cultured in normoxia, and activation was abrogated by DAPT (Fig. $4 a, b$ ).

To assess how Notch induction of HIF2 $\alpha$ affected gene expression globally, we activated Notch1 signaling by tamoxifen in DAOY cells stably expressing NERT2
A

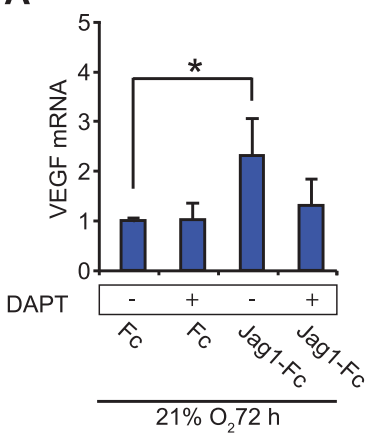

B

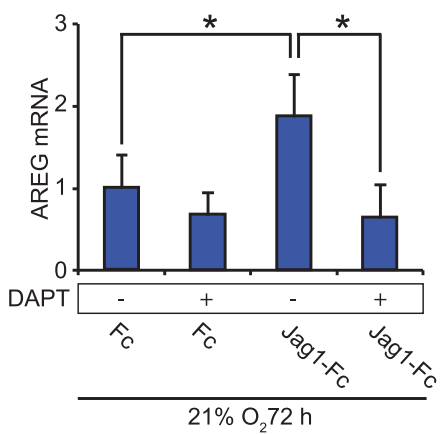

D
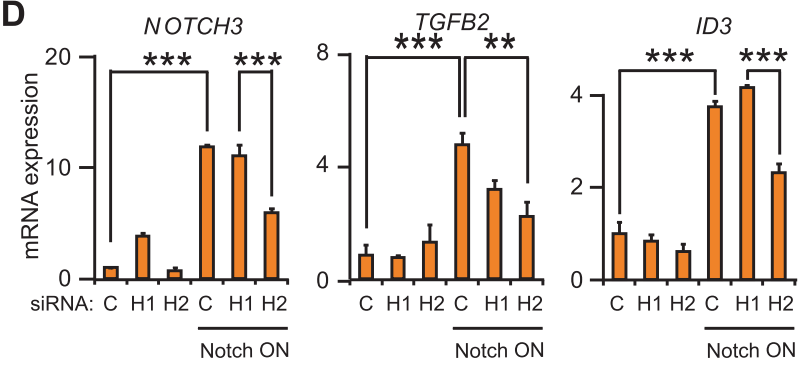

$\mathbf{E}$
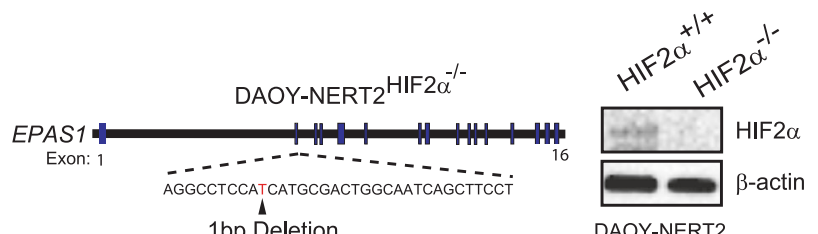

C

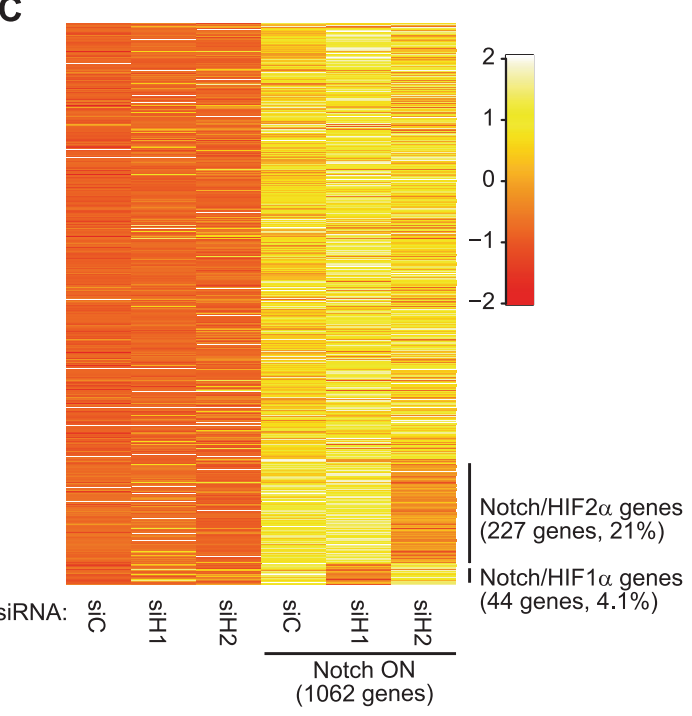

$\mathbf{F}$

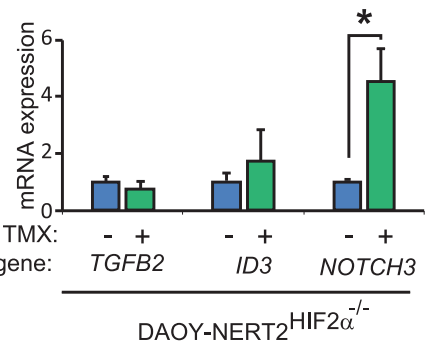

Fig. 4 HIF $2 \alpha$ is required for a portion of the Notch-induced transcriptome to be activated. (a, b) VEGF (a) and AREG (b) mRNA expression in MDA-MB-231 breast cancer cells cultured on immobilized Jagged1 ligands (Jag1-Fc), or control fragments $(\mathrm{Fc})$, cultured at $21 \% \mathrm{O}_{2}$ for $72 \mathrm{~h}$ in combination with DAPT treatment, as indicated. c Heatmap of Notch-activated genes in DAOY-NERT2 cells subjected to either HIF1 $\alpha(\mathrm{H} 1)$ or HIF2 $\alpha$ (H2) siRNA-knockdown (see also Supplementary Figure 4). A total of 1062 genes were upregulated by activated Notch signaling (Notch ON) in normoxia, of which 227 genes were downregulated by HIF $2 \alpha$ siRNA knockdown, and 44 genes by HIF1 $\alpha$ siRNA knockdown. d mRNA expression levels, measured by qPCR, of three genes (NOTCH3, TGFB2, and ID3) from (c). e Schematic representation of the CRISPR/Cas9 targeting strategy for the HIF2 $\alpha$ gene $(E P A S 1)$ to generate DAOY-NERT2 $2^{\mathrm{HIF} 2 \alpha-/-}$ cells, with a Western blot showing targeting efficiency. $\mathbf{f}$ mRNA expression levels, measured by qPCR, of NOTCH3, TGFB2, and ID3 in DAOY$\mathrm{NERT} 2^{\mathrm{HIF} 2 \alpha-1-}$ cells with and without tamoxifen treatment (TMX) to activate Notch signaling. Values are significant at $* * * p<0.001, * * p$ $<0.01$, and $* p<0.05$. Graphs represent an average of at least three independent experiments 
(DAOY-NERT2) for $48 \mathrm{~h}$ under normoxia and hypoxia, in combination with siRNA-mediated depletion of HIF $1 \alpha$ or HIF2 $\alpha$ (Supplementary Figure 4A, B). Genome-wide RNAsequencing analysis revealed that 1062 genes were upregulated upon Notch activation in normoxia, 881 genes in hypoxia, and 547 genes were upregulated by Notch in both normoxia and hypoxia, including the canonical Notch targets NRARP, HES4, and HEY1 (Supplementary Figure 4C). A total of 227 of the 1062 genes $(21 \%)$ induced by Notch in normoxia were downregulated by HIF2 $\alpha$ siRNA knockdown (Fig. 4c, Supplementary File 1). In contrast, only 44 of the 1062 Notch-activated genes (4.1\%) were downregulated by HIF1 $\alpha$ knockdown (Fig. 4c, Supplementary File 1). These data suggest that a substantial proportion of the normoxic Notch transcriptome in medulloblastoma requires HIF $2 \alpha$, but not HIF1 $\alpha$, for activation. A small set of genes $(4.7 \%)$ was also regulated both by HIF $1 \alpha$ and HIF $2 \alpha$ (Supplementary File1). Enrichment analysis of functional annotation Gene Ontology terms revealed that several of the 227 Notch-activated and HIF $2 \alpha-$ dependent genes are involved in cell adhesion, blood vessel development, and signal transduction (Supplementary table 1). qPCR validation of three of these genes, Notch3, TGFB2, and ID3, showed a normoxic Notch induction, which was blunted by siRNA to HIF2 $\alpha$ (Fig. 4d). Similarly, in DAOY-NERT2 HIF2 $\alpha$ knockout cells (Fig. 4e), TGFB2 and ID3 expression was not upregulated by tamoxifeninduced activation of Notch1 ICD, and upregulation of Notch3 was reduced (Fig. 4f) as compared to a level comparable to that obtained by siRNA for HIF2 $\alpha$ in Fig. $4 d$. Overall, these data suggest that a substantial subset of the Notch-induced transcriptome requires functional HIF2 $\alpha$.

\section{Notch receptor paralog-specific effects on medulloblastoma tumor growth}

We next assessed how altered Notch and HIF2 $\alpha$ signaling impacts on the tumor potential of DAOY cells. We first explored how Notch1 or Notch2 expression affected growth of DAOY cells using the chorioallantoic membrane (CAM) xenograft model [37]. Enhanced tumor growth was observed in the CAM assay after Notch2 ICD, but not Notch1 ICD, expression (Fig. 5a). To further assess Notch paralog specificity, we inactivated Notch1 or Notch2 using CRISPR/Cas9, generating $\mathrm{DAOY}^{\text {Notch1-l- }}$ and $\mathrm{DAOY}^{\mathrm{Notch} 2-l-}$ cells, respectively (Fig. 5b). Growth rates of DAOY ${ }^{\mathrm{Notch} 1-/-}$ cells were very similar to that of control DAOY cells, whereas DAOY ${ }^{\text {Notch2-I- }}$ cells showed markedly reduced growth (Fig. $5 c$ ), corroborating a specific role for Notch2 in medulloblastoma tumor growth [51]. Transcriptomic analysis of the

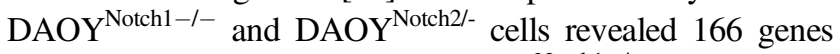
that were upregulated in both DAOY ${ }^{\text {Notch1-/- }}$ and DAOYNotch2-I- cells, but also 541 genes specifically upregulated in the DAOY ${ }^{\text {Notch2-I- }}$ cells (including EEF1A2 and ITGBL1), and 349 genes specifically upregulated only in the DAOYNotch1-I- cells (including WISPI and HCLS1) (Fig. 5d; Supplementary File 2). A total of 195 genes were downregulated in both DAOY ${ }^{\text {Notch1-I- }}$ and DAOY ${ }^{\text {Notch2-I- }}$ cells, while 270 genes were specifically downregulated in the DAOY ${ }^{\text {Notch2-1- }}$ cells (including DNER and PID1), and 825 genes (including $G D A$ and $I T G B 4$ ) were downregulated only in the DAOYNotch1-I- cells (Fig. 5e, Supplementary File 2). In sum, these data corroborate the notion that Notch1 and Notch2 play different roles in medulloblastoma tumor growth.

To study how changes in HIF2 $\alpha$ signaling affect growth of DAOY cells, we induced Notch1 signaling in DAOYNERT2 cells ablated for HIF2 $\alpha$ (DAOY-NERT2 ${ }^{\mathrm{HIF} 2 \alpha-1-}$ cells; see Fig. $4 \mathrm{e}$ for HIF $2 \alpha$ targeting) or in DAOYNERT $^{\mathrm{HIF} 2 \alpha+/+}$ control cells. Tamoxifen induction of Notch1 ICD in DAOY-NERT2 ${ }^{\mathrm{HIF} 2 \alpha+/+}$ cells resulted in upregulation of $H E Y 1$ and $N O T C H 3$ (Fig. 5f), and did not promote tumor growth (Fig. 5g), in keeping with the data in Fig. 5a. In contrast, DAOY-NERT2 $2^{\mathrm{HIF} 2 \alpha-/-}$ cells exhibited more rapid tumor growth than the control cells, which was partially reduced by Notch1 ICD expression by tamoxifen (Fig. $5 \mathrm{~g}$ ). The reason why elevated Notch1 ICD levels specifically led to a decrease in tumor growth from DAOY-NERT2 $2^{\mathrm{HIF} 2 \alpha-I-}$ cells but not from DAOY-NERT2 ${ }^{\mathrm{HIF} 2 \alpha+/+}$ control cells (Fig. $5 \mathrm{~g}$ ) is not understood. It is not likely explained by Notch1 ICD reducing the level of HIF $1 \alpha$, as this was not observed in DAOY cells under hypoxia-mimicking conditions (Fig. 3c). Instead, the large number of genes showing altered expression in response to Notch1-deficiency but not Notch2deficiency (Fig. 5d, e) may suggest that there exists Notch1specific growth-suppressing genes, whose functions are unleashed only in the absence of HIF2 $\alpha$.

We next considered the possibility that loss of HIF $2 \alpha$ may increase HIF1 $\alpha$ protein levels, leading to the promotion of tumor growth. In support of this idea, DAOYNERT2 ${ }^{\text {HIF } 2 \alpha-I-}$ cells exhibited higher HIF1 $\alpha$ protein levels under hypoxic conditions (Fig. 5h) and treatment of the DAOY-NERT2 $2^{\mathrm{HIF} 2 \alpha-/-}$ cells with the HIF1 $\alpha$ inhibitor KC7F2 reduced tumor growth both under control and Notch1 ICD-activated conditions (Fig. 5i). In conclusion, these data suggest that the different $\mathrm{HIF} \alpha$ and Notch receptor paralogs exert specific effects on the tumor growth of medulloblastoma cells.

\section{Discussion}

Dysregulation of Notch and hypoxia signaling contributes to tumor initiation and development, and it is therefore important to gain molecular insights into how these two signaling mechanisms intersect in a tumor context. It has previously been established that hypoxia regulates Notch 
A

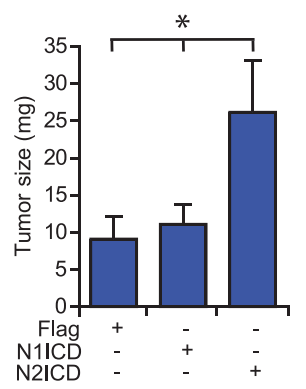

D

Notch $1 \% \quad$ Notch $2 \%$

E

Notch1\% Notch2\%
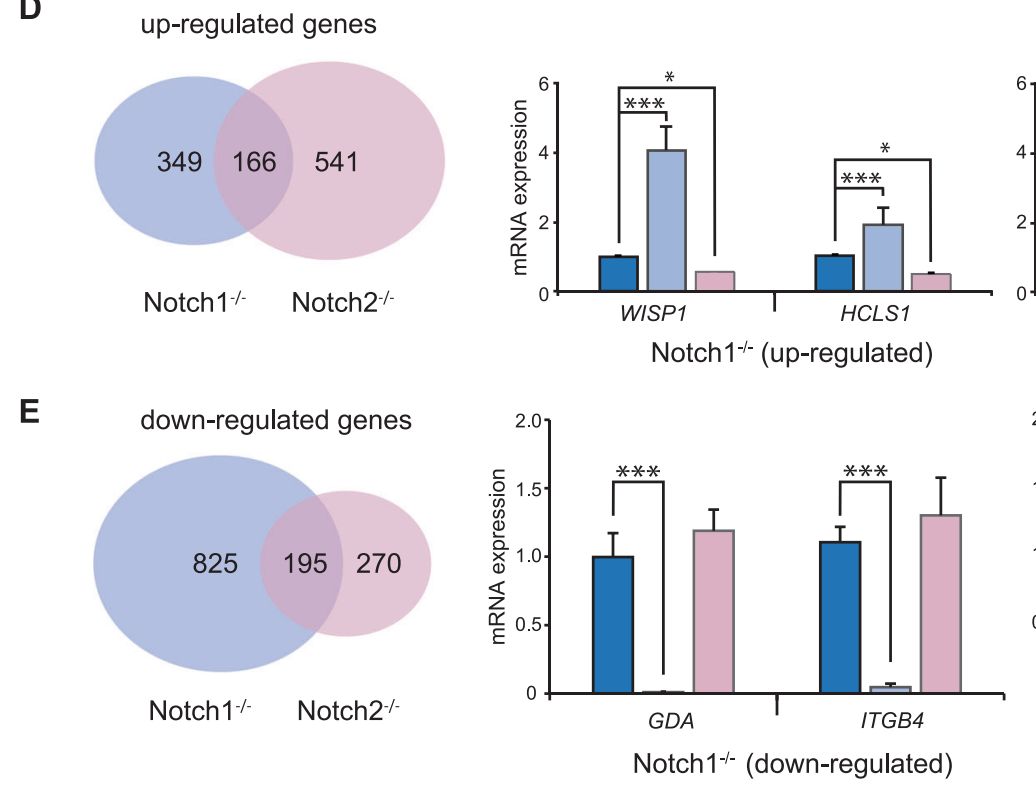

B

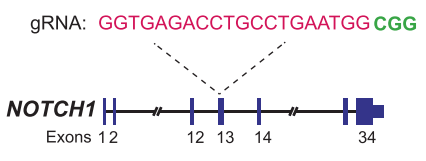

gRNA: GGTGGAGCCTGGAGTACAGGAGG

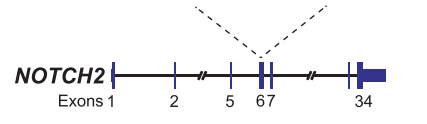

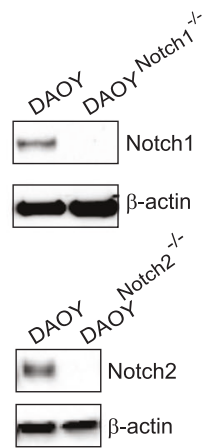

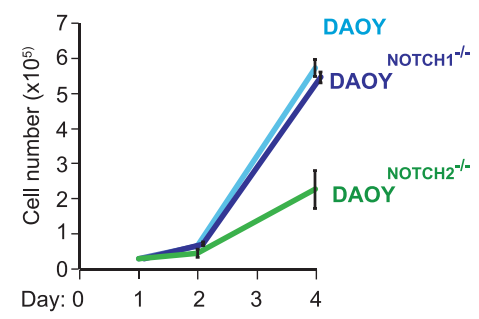

C

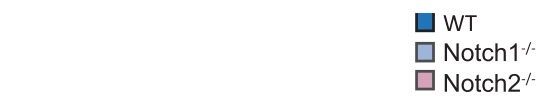

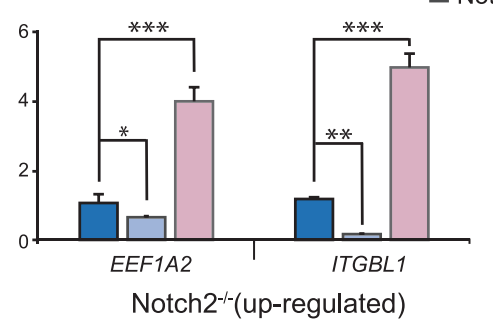

Notch2-1(up-regulated)

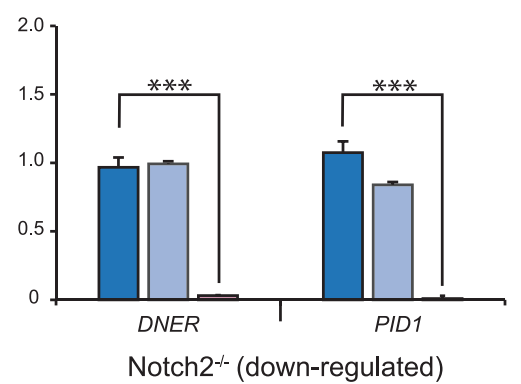

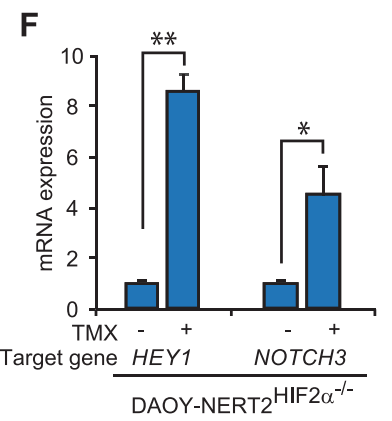

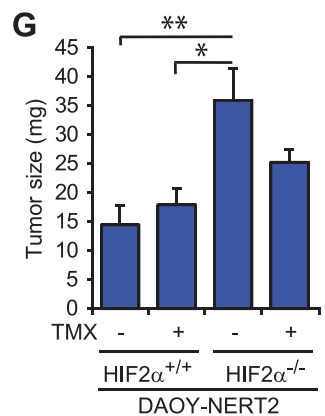

Fig. 5 Notch1 and 2 ICD exert distinct effects on tumor growth. a Analysis of tumor growth in the chick chorioallantoic membrane (CAM) assay following overexpression of Notch1 or 2 ICD, as indicated. b Schematic representation of the CRISPR/Cas9 targeting strategy for the Notch1 and Notch2 genes (left) and protein levels measured by Western blotting in DAOY, DAOY ${ }^{\text {Notch1-I- }}$, and DAOY ${ }^{\text {Notch2-I- }}$ cells. c Analysis of cell growth for DAOY, DAOYNotch1-I- , and DAOY ${ }^{\text {Notch2-I- }}$ cells. d, e VENN diagrams describing differentially expressed genes between DAOY ${ }^{\text {Notch1-I- }}$ and DAOYNotch2-I- cells, as compared to DAOY control cells, from transcriptomic analysis of these cells (left). Examples of genes specifically upregulated in DAOY ${ }^{\text {Notch1-I- }}$ (WISP1 and HCLS1) and DAOY ${ }^{\text {Notch2-I- }}$ (EEF1A2
H

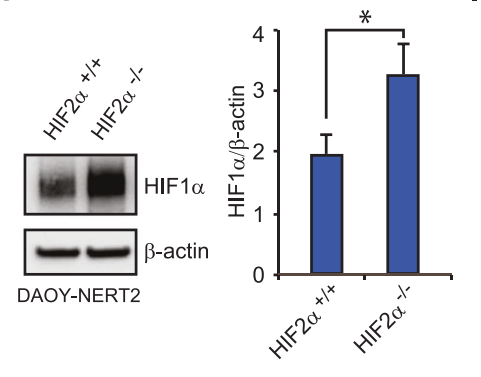

and $I T B G L 1)$ cells $(\mathbf{d})$, or downregulated in DAOY ${ }^{\text {Notch1-I- }}$ (GDA and $I T G B 4))$ and DAOY ${ }^{\text {Notch2-l- }}$ (DNER and PID1) cells (e) are shown to the right. $\mathbf{f}$ mRNA expression levels measured by qPCR for $H E Y 1$ and NOTCH3 in DAOY-NERT2 ${ }^{\mathrm{HIF} 2 \alpha-/-}$ cells treated with a tamoxifen to activate Notch signaling. g Analysis of tumor growth of Notch1activated DAOY-NERT2 $2^{\mathrm{HIF} 2 \alpha+/+}$ or DAOY-NERT2 $2^{\mathrm{HIF} 2 \alpha-I-}$ cells, using the CAM assay. $\mathbf{h}$ Western blot of HIF1 $\alpha$ protein levels in DAOY ${ }^{\mathrm{HIF} 2 \alpha+/+}$ and DAOY ${ }^{\mathrm{HIF} 2 \alpha-l-}$ cells (quantification to the right). i Effects on tumor growth of the DAOY-NERT2 ${ }^{\mathrm{HIF} 2 \alpha-l-}$ cells after treatment with the HIF1 $\alpha$ inhibitor KC7F2 at $40 \mu \mathrm{M}$. Values are significant at $* * * p<0.001$, $* * p<0.01$, and $* p<0.05$. Graphs represent an average of at least three independent experiments 
signaling activity, but less is known about how changes in Notch signaling activity affect the cellular hypoxic response [24]. In this report, we provide evidence that elevated Notch signaling promotes a HIF $2 \alpha$-driven hypoxic response.

Our data suggest that Notch upregulates HIF $2 \alpha$ at the transcriptional level, and that engagement of the Notch1 ICD/MAML1/CSL transcriptional complex is required. This notion is based on the observation that a Notch1 ICDER fusion protein (NERT2) did not upregulate HIF2 $\alpha$ mRNA levels when Notch1 ICD localized in the cytoplasm, but only after nuclear localization following tamoxifen treatment. Moreover, disruption of the canonical Notch transcriptional activation complex, by inactivation of the CSL gene or expression of dominant negative MAML1, abrogated HIF $2 \alpha$ mRNA upregulation. However, Notch1 ICD/MAML1/CSL does not seem to directly activate HIF $2 \alpha$ at the proximal promoter level since: (i) the HIF $2 \alpha$ mRNA upregulation was sensitive to the protein synthesis inhibitor CHX; (ii) ChIP-seq analysis revealed that there are no DNA sites showing specific CSL occupancy in the HIF $2 \alpha$ promoter or gene; and (iii) the HIF2 $\alpha$ promoter encompassing $1.5 \mathrm{~kb}$ sequence around the HIF $2 \alpha$ transcription start site was unresponsive to Notch activation. This indicates the need for a yet unidentified intermediate protein in the Notch-induced HIF $2 \alpha$ activation, which would need to be synthesized prior to HIF2 $\alpha$ upregulation.

Despite that HIF2 $\alpha$ protein normally is degraded in normoxia, HIF2 $\alpha$ mRNA upregulation in normoxia led to accumulation of HIF $2 \alpha$ protein in several of the tumor cells tested. The degree of HIF2 $\alpha$ accumulation is likely linked to the magnitude of the Notch signaling induction, as a strong induction of Notch signaling (by Notch1 ICD expression) led to higher HIF2 $\alpha$ protein levels also observed in normoxia, whereas more moderate Notch activation levels, mediated by ligand stimulation, were insufficient to increase HIF2 $\alpha$ protein across all cell lines tested during normoxia, although sufficient during hypoxia. This suggests that sufficiently induced levels of HIF $2 \alpha$ mRNA and protein in normoxia may override the ubiquitination-mediated degradation machinery. In keeping with this notion, overexpression of HIF $2 \alpha$ from an exogenous promoter also resulted in robust HIF2 $\alpha$ protein levels at normoxia.

In several of the cell types tested, HIF $2 \alpha$ activation by Notch correlated with decreased HIF1 $\alpha$ protein levels, suggesting that high levels of Notch signaling induces a HIF1 $\alpha$-to-HIF2 $\alpha$ switch. The reciprocal regulation of HIF $1 \alpha$ and HIF $2 \alpha$ was observed in primary breast cancer cells and in MDA-MB-231 cells after $72 \mathrm{~h}$ of Jagged1-stimulation, as well as in Notch-activated medulloblastoma D324 cells when cells were treated with $\mathrm{CoCl}_{2}$, a frequently utilized hypoxia-mimetic. A HIF1 $\alpha$-to-HIF $2 \alpha$ switch has been previously observed, notably in neuroblastoma cells exposed to prolonged hypoxia $[15,16]$, but the mechanism behind the switch remains elusive. One possible explanation for the switch is that the Notch-induced rise in HIF $2 \alpha$ protein levels triggers the reduction of HIF1 $\alpha$, which would be compatible with our findings described above. However, it should be noted that HIF1 $\alpha$ reduction upon induction of HIF $2 \alpha$ by Notch was not observed in all cell types tested, for example in DAOY cells (Fig. 3c), although conversely HIF2 $\alpha$ depletion by CRISPR/Cas9 resulted in increased amounts of HIF1 $\alpha$ protein. Alternatively, reduction of HIF1 $\alpha$ levels may elicit an increase in HIF $2 \alpha$ levels, or the regulation of the levels of HIF $1 \alpha$ and HIF $2 \alpha$ may be independently regulated. As Notch regulates HIF $2 \alpha$ expression, the first hypothesis, i.e., HIF2 $\alpha$ controls the level of HIF1 $\alpha$, may appear likely. Our data may also suggest that Notch activation triggers HIF $1 \alpha$ degradation via $\gamma$-secretase-dependent upregulation of the ubiquitin ligase CHIP, a mediator of HIF1 $\alpha$ degradation. More work is however needed to understand the effects of Notch on the HIF1 $\alpha$-to-HIF2 $\alpha$ switch, and why it occurs only in certain cell types.

Through genome-wide transcriptomic analysis of DAOY cells, we found that a substantial portion of the Notchinduced transcriptome in normoxia requires the presence of HIF $2 \alpha$, as approximately $21 \%$ of all Notch-induced genes was abrogated by siRNA-mediated knockdown of HIF $2 \alpha$. This contrasted with siRNA-mediated knockdown of HIF1 $\alpha$, which affected the Notch transcriptome to a considerably lesser extent (4.1\% of the Notch-induced genes). The most parsimonious explanation for this observation is that Notch upregulates HIF2 $\alpha$, which in turn activates its specific subset of target genes, even under normoxic conditions. This scenario is reminiscent of the relationship between Notch and the transcription factor $\mathrm{cMyc}$, where Notch activation of cMyc leads to complex and overlapping transcriptional responses [52, 53]. A HIF2 $\alpha$-dependent subset of the Notch-induced transcriptome is potentially interesting from a cancer therapy development perspective. There are not yet any functional Notch inhibitors in clinical use [54], but if key tumor-promoting features of hyperactivated Notch signaling would stem from a HIF2 $\alpha$ dependent portion of the Notch transcriptome, blocking HIF $2 \alpha$ would represent an interesting alternative approach to curtail the adverse effects of dysregulated Notch signaling. Recently, specific HIF2 $\alpha$ inhibitors that bind to a unique cavity in HIF2 $\alpha$ were developed $[55,56]$. These inhibitors have proven effective in preclinical ccRCC models and in a ccRCC patient $[57,58]$ (for review see [19]); and it may be interesting to explore their efficacy in blocking aspects of Notch-induced transcriptomes. Additionally, targeting HAF, which is required for the transcriptional activity of HIF2 $\alpha$, may represent an alternative strategy [59]. In conclusion, our data show that Notch signaling regulates HIF2 $\alpha$, a key component in the cellular 
hypoxic response, and provide an important new facet to how Notch signaling and the cellular hypoxic response interact in tumor cells.

\section{Materials and methods}

\section{Cell culture}

The 786-O, RAW264.7, MCF-7, MDA-MB-231, A549, SKN-BE(2)C, U251, MCF10A, and DAOY (HTB186) cells were purchased from American Type Culture Collection (ATCC). The primary glioblastoma cells were kindly provided by Drs. Monica Nistér and Johan Holmberg (Karolinska Institutet). Anonymized human breast cancer cells were kindly provided by Dr. Johan Hartman (Ethical permit: Regionala Etikprövningsnämnden i Stockholm 2016/ 937-32). Culture conditions are specified in the Supplementary information.

\section{Real-time quantitative-PCR analysis}

RNA extraction and cDNA synthesis were accomplished as previously described [60]. Real-time PCR analysis was carried out on a 7500 Fast Real-Time PCR system with Fast SYBR Green Master Mix (Applied Biosystems) according to the manufacturer's recommendations. The primers were synthesized by Eurofin MWG Operon, and sequences are shown in the Supplementary Figure 5. cDNA from Notchactivated primary mesenchymal cells was a kind gift from Dr. Katarina Le Blanc (Karolinska Institutet).

\section{Western blot analysis and antibodies}

For Western blot analysis, cells were lysed in RIPA buffer supplemented with protease inhibitor cocktail (Complete, Roche). Hypoxia treated cells were lysed within the hypoxia chamber. Protein concentration was determined with the Pierce BCA protein assay kit (Thermo Scientific). Protein samples were boiled at $95^{\circ} \mathrm{C}$ for $5 \mathrm{~min}$, where after $50 \mu \mathrm{g}$ was loaded per well in Nu-PAGE 4-12\% Bis-Tris gels (Life Technologies) for SDS-PAGE, and then transferred to Protein nitrocellulose membranes (Schleicher and Schuell). Membranes were blocked for $1 \mathrm{~h}$ using Odyssey blocking buffer (LI-COR Biosciences), and incubated with the primary antibody, sometimes in combination with the SignalBoost Immunoreaction Enhancer Kit (EMD Millipore), overnight at $+4{ }^{\circ} \mathrm{C}$ with end-over-end rotation. Immunoblots were visualized with the Odyssey Infrared Imaging system (LI-COR Biosciences) in accordance with the manufacturer's recommendations. Antibodies are listed in the Supplementary information.
Activation of Notch signaling by immobilized ligands

Notch activation by immobilized ligands was performed as previously described [61, 62].

\section{Statistical analysis}

Two-sided Student's $t$ test was used to determine if treatments were significantly different from each other, where $p \leq 0.05$ was considered statistically significant. Error bars represent standard deviation of the mean.

\section{ChIP-seq analysis}

The procedures for CSL chromatin precipitation (ChIP) and the ChIP-seq experiments are provided in the Supplementary information.

Acknowledgements The financial support from the Swedish Cancer Society, the Swedish Research Council, the BRECT Consortium at Karolinska Institutet, and ICMC (AstraZeneca) (UL) is gratefully acknowledged. SKJL was supported by the Jane \& Aatos Erkko and Albin K. Johanssons Foundations. This work is dedicated to the memory of the late friend and colleague Lorenz Poellinger.

\section{Compliance with ethical standards}

Conflict of interest UL holds research grants from Merck AG and AstraZeneca, no personal remuneration. JB has received research support from Amgen, AstraZeneca, Bayer, Merck, Pfizer, Roche, and Sanofi-Aventis with payments to the Karolinska Institutet and/or Karolinska University Hospital, no personal remuneration. JB has received personal payments for being co-author in UpToDate.

Open Access This article is licensed under a Creative Commons Attribution 4.0 International License, which permits use, sharing, adaptation, distribution and reproduction in any medium or format, as long as you give appropriate credit to the original author(s) and the source, provide a link to the Creative Commons license, and indicate if changes were made. The images or other third party material in this article are included in the article's Creative Commons license, unless indicated otherwise in a credit line to the material. If material is not included in the article's Creative Commons license and your intended use is not permitted by statutory regulation or exceeds the permitted use, you will need to obtain permission directly from the copyright holder. To view a copy of this license, visit http://creativecommons. org/licenses/by/4.0/.

\section{References}

1. Bray SJ. Notch signalling in context. Nat Rev Mol Cell Biol. 2016;9:722-35.

2. Siebel C, Lendahl U. Notch signaling in development, tissue homeostasis, and disease. Physiol Rev. 2017;97:1235-94.

3. Aster JC, Pear WS, Blacklow SC. The varied roles of Notch in cancer. Annu Rev Pathol Mech Dis. 2017;12:245-75.

4. Semenza GL. Oxygen sensing, homeostasis, and disease. N Engl J Med. 2011;365:537-47. 
5. Zhao J, Du F, Luo Y, Shen G, Zheng F, Xu B. The emerging role of hypoxia-inducible factor-2 involved in chemo/radioresistance in solid tumors. Cancer Treat Rev. 2015;41:623-33.

6. Rankin EB, Biju MP, Liu Q, Unger TL, Rha J, Johnson RS, et al. Hypoxia-inducible factor-2 (HIF-2) regulates hepatic erythropoietin in vivo. J Clin Invest. 2007;117:1068-77.

7. Benita Y, Kikuchi H, Smith AD, Zhang MQ, Chung DC, Xavier RJ. An integrative genomics approach identifies hypoxia inducible factor-1 (HIF-1)-target genes that form the core response to hypoxia. Nucleic Acids Res. 2009;37:4587-602.

8. Covello KL, Kehler J, Yu H, Gordan JD, Arsham AM, Hu CJ, et al. HIF-2alpha regulates Oct-4: effects of hypoxia on stem cell function, embryonic development, and tumor growth. Genes Dev. 2006;20:557-70

9. Manalo DJ, Rowan A, Lavoie T, Natarajan L, Kelly BD, Ye SQ, et al. Transcriptional regulation of vascular endothelial cell responses to hypoxia by HIF-1. Blood. 2005;105:659-69.

10. Raval RR, Lau KW, Tran MGB, Heidi M, Mandriota SJ, Li J, et al. Contrasting properties of HIF-2 in von Hippel-Lindauassociated renal cell carcinoma contrasting properties of hypoxiainducible factor 1 (HIF-1) and HIF-2 in von Hippel-Lindauassociated renal cell carcinoma. Mol Cell Biol. 2005;1:5675-86.

11. Keith B, Johnson RS, Simon MC. HIF1 $\alpha$ and HIF2 $\alpha$ : sibling rivalry in hypoxic tumour growth and progression. Nat Rev Cancer. 2012;12:9-22.

12. Hu C, Wang L, Chodosh LA, Keith B, Simon MC. Differential roles of hypoxia-inducible factor 1 alpha (HIF-1 alpha) and HIF-2 alpha in hypoxic gene regulation. Mol Cell Biol. 2003;23:9361-74.

13. Petrella BL, Lohi J, Brinckerhoff CE. Identification of membrane type-1 matrix metalloproteinase as a target of hypoxia-inducible factor-2 alpha in von Hippel-Lindau renal cell carcinoma. Oncogene. 2005;24:1043-52.

14. Wang V, Davis DA, Haque M, Huang LE, Yarchoan R. Differential gene up-regulation by hypoxia-inducible factor-1A and hypoxia-inducible factor-2A A in HEK293T cells. Cancer Res. 2005;65:3299-306.

15. Holmquist-Mengelbier L, Fredlund E, Löfstedt T, Noguera R, Navarro S, Nilsson H, et al. Recruitment of HIF-1a and HIF-2a to common target genes is differentially regulated in neuroblastoma: HIF-2a promotes an aggressive phenotype. Cancer Cell. 2006;10:413-23.

16. Uchida T, Rossignol F, Matthay MA, Mounier R, Couette S, Clottes E, et al. Prolonged hypoxia differentially regulates hypoxia-inducible factor (HIF)- $1 \alpha$ and HIF-2 $\alpha$ expression in lung epithelial cells: implication of natural antisense HIF-1 $\alpha$. J Biol Chem. 2004;279:14871-8.

17. Koh MY, Lemos R, Liu X, Powis G. The hypoxia-associated factor switches cells from HIF-1a- to HIF-2a-dependent signaling promoting stem cell characteristics, aggressive tumor growth and invasion. Cancer Res. 2011;71:4015-27.

18. Wettersten HI, Aboud OA, Lara PN, Weiss RH. Metabolic reprogramming in clear cell renal cell carcinoma. Nat Rev Nephrol. 2017;13:410-9.

19. Toledo R. New HIF2a inhibitors: potential implications as therapeutics for advanced phenochromocytomas and paragangliomas. Endocr Relat Cancer. 2017;24:C9-C19.

20. Zhuang Z, Yang C, Lorenzo F, Merino M, Fojo T, Kebebew E, et al. Somatic HIF2A gain-of-function mutations in paraganglioma with polycythemia. N Engl J Med. 2012;367:922-30.

21. Favier J, Buffet A, Gimenez-Roqueplo A-P. HIF2A mutations in paraganglioma with polycythemia. $\mathrm{N}$ Engl $\mathrm{J}$ Med. 2012;367:2161-2.

22. Toledo RA, Qin Y, Srikantan S, Morales NP, Li Q, Deng Y, et al. In vivo and in vitro oncogenic effects of HIF2A mutations in pheochromocytomas and paragangliomas. Endocr Relat Cancer. 2013;20:349-59.

23. Burroughs SK, Kaluz S, Wang D, Wang K, Van Meir EG, Wang B. Hypoxia inducible factor pathway inhibitors as anticancer therapeutics. Futur Med Chem. 2013;5:553-72.

24. Landor SK-J, Lendahl U. The interplay between the cellular hypoxic response and Notch signaling. Exp Cell Res. 2017;356:146-51

25. Gustafsson MV, Zheng X, Pereira T, Gradin K, Jin S, Lundkvist J, et al. Hypoxia requires notch signaling to maintain the undifferentiated cell state. Dev Cell. 2005;9:617-28.

26. Bertout JA, Patel SA, Fryer BH, Durham AC, Covello KL, Olive $\mathrm{KP}$, et al. Heterozygosity for hypoxia inducible factor 1a decreases the incidence of thymic lymphomas in a p53 mutant mouse model. Cancer Res. 2009;69:3213-20.

27. Pistollato F, Rampazzo E, Persano L, Abbadi S, Frasson C, Denaro $\mathrm{L}$, et al. Interaction of hypoxia-inducible factor-1a and Notch signaling regulates medulloblastoma precursor proliferation and fate. Stem Cells. 2010;28:1918-29.

28. Qiang L, Wu T, Zhang H-W, Lu N, Hu R, Wang Y-J, et al. HIF$1 \alpha$ is critical for hypoxia-mediated maintenance of glioblastoma stem cells by activating Notch signaling pathway. Cell Death Differ. 2011;19:284-94.

29. Pietras A, Hansford LM, Johnsson AS, Bridges E, Sjolund J, Gisselsson D, et al. HIF-2alpha maintains an undifferentiated state in neural crest-like human neuroblastoma tumor-initiating cells. Proc Natl Acad Sci USA. 2009;106:16805-10.

30. Danza G, Di Serio C, Rosati F, Lonetto G, Sturli N, Kacer D, et al. Notch signaling modulates hypoxia-induced neuroendocrine differentiation of human prostate cancer cells. Mol Cancer Res. 2012;10:230-8.

31. Meunier A, Flores AN, McDermott N, Rivera-Figueroa K, Perry A, Lynch T, et al. Hypoxia regulates Notch-3 mRNA and receptor activation in prostate cancer cells. Heliyon. 2016;2:e00104.

32. Xing F, Okuda H, Watabe M, Kobayashi A, Pai SK, Liu W, et al. Hypoxia-induced Jagged2 promotes breast cancer metastasis and self-renewal of cancer stem-like cells. Oncogene. 2011;30:4075-86.

33. Pietras A, Stedingk K, von, Lindgren D, Påhlman S, Axelson H. JAG2 Induction in hypoxic tumor cells alters Notch signaling and enhances endothelial cell tube formation. Mol Cancer Res. 2011;9:626-36.

34. Lim KJ, Brandt WD, Heth JA, Muraszko KM, Fan X, Bar EE, et al. Lateral inhibition of Notch signaling in neoplastic cells. Oncotarget. 2015;6:1666-77.

35. Lanner F, Lee KL, Ortega GC, Sohl M, Li X, Jin S, et al. Hypoxia-induced arterial differentiation requires adrenomedullin and notch signaling. Stem Cells Dev. 2013;22:1360-9.

36. Gao W, Sweeney C, Connolly M, Kennedy A, Ng CT, McCormick $\mathbf{J}$, et al. Notch-1 mediates hypoxia-induced angiogenesis in rheumatoid arthritis. Arthritis Rheum. 2012;64:2104-13.

37. Braune E-B, Tsoi YL, Phoon YP, Landor S, Silva Cascales H, Ramsköld D, et al. Loss of CSL unlocks a hypoxic response and enhanced tumor growth potential in breast cancer cells. Stem Cell Rep. 2016;6:1-9.

38. Main H, Lee KL, Yang H, Haapa-Paananen S, Edgren H, Jin S, et al. Interactions between Notch- and hypoxia-induced transcriptomes in embryonic stem cells. Exp Cell Res. 2010;316:1610-24.

39. Pirot P, van Grunsven LA, Marine J-C, Huylebroeck D, Bellefroid EJ. Direct regulation of the Nrarp gene promoter by the Notch signaling pathway. Biochem Biophys Res Commun. 2004;322:526-34.

40. Kilpinen S, Autio R, Ojala K, Iljin K, Bucher E, Sara H, et al. Systematic bioinformatic analysis of expression levels of 17,330 
human genes across 9,783 samples from 175 types of healthy and pathological tissues. Genome Biol. 2008;9:R139.

41. Andersson ER, Sandberg R, Lendahl U. Notch signaling: simplicity in design, versatility in function. Development. 2011;138:3593-612.

42. Jin S, Mutvei AP, Chivukula IV, Andersson ER, Ramsköld D, Sandberg R, et al. Non-canonical Notch signaling activates IL-6/ JAK/STAT signaling in breast tumor cells and is controlled by p53 and IKK $\alpha /$ IKK $\beta$. Oncogene. 2013;32:4892-4902.

43. Sethi N, Dai X, Winter CG, Kang Y. Tumor-derived JAGGED1 promotes osteolytic bone metastasis of breast cancer by engaging notch signaling in bone cells. Cancer Cell. 2011;19:192-205.

44. Ayaz F, Osborne BA. Non-canonical Notch signaling in cancer and immunity. Front Oncol. 2014;4:1-6.

45. Martini S, Bernoth K, Main H, Ortega GDC, Lendahl U, Just U, et al. A critical role for Sox9 in notch-induced astrogliogenesis and stem cell maintenance. Stem Cells. 2012;31:741-51.

46. Schroeder T, Just U. Notch signalling via RBP-J promotes myeloid differentiation. EMBO J. 2000;19:2558-68.

47. Maillard I, Weng AP, Carpenter AC, Rodriguez CG, Sai H, Xu L, et al. Mastermind critically regulates Notch-mediated lymphoid cell fate decisions. Blood. 2004;104:1696-702.

48. Luo W, Zhong J, Chang R, Hu H, Pandey A, Semenza GL. Hsp70 and CHIP selectively mediate ubiquitination and degradation of hypoxia-inducible factor (HIF)-1a but not HIF-2a. J Biol Chem. 2010;285:3651-63.

49. Brogi E, Schatteman G, Wu T, Kim EA, Varticovski L, Keyt B, et al. Hypoxia-induced paracrine regulation of vascular endothelial growth factor receptor expression. J Clin Invest. 1996;97:469-76.

50. O'Reilly SM, Leonard MO, Kieran N, Comerford KM, Cummins E, Pouliot M, et al. Hypoxia induces epithelial amphiregulin gene expression in a CREB-dependent manner. Am J Physiol Cell Physiol. 2006;290:C592-C600.

51. Fan X, Mikolaenko I, Elhassan I, Ni X, Wang Y, Ball D, et al. Notch1 and Notch2 have opposite effects on embryonal brain tumor growth. Cancer Res. 2004;64:7787-93.
52. Herranz D, Ambesi-Impiombato A, Palomero T, Schnell SA, Belver L, Wendorff AA, et al. A NOTCH1-driven MYC enhancer promotes $\mathrm{T}$ cell development, transformation and acute lymphoblastic leukemia. Nat Med. 2014;20:1130-7.

53. Palomero T, Lim WK, Odom DT, Sulis ML, Real PJ, Margolin A, et al. NOTCH1 directly regulates c-MYC and activates a feedforward-loop transcriptional network promoting leukemic cell growth. Proc Natl Acad Sci USA. 2006;103:18261-6.

54. Andersson ER, Lendahl U. Therapeutic modulation of Notch signalling--are we there yet? Nat Rev Drug Discov. 2014;13:357-78

55. Scheuermann TH, Stroud D, Sleet CE, Bayeh L, Shokri C, Wang $\mathrm{H}$, et al. Isoform-selective and stereoselective inhibition of hypoxia inducible factor-2. J Med Chem. 2015;58:5930-41.

56. Scheuermann TH, Li Q, Ma H-W, Key J, Zhang L, Chen R, et al. Allosteric inhibition of hypoxia inducible factor-2 with small molecules. Nat Chem Biol. 2013;9:271-6.

57. Chen W, Hill H, Christie A, Kim MS, Holloman E, Pavia-Jimenez A, et al. Targeting renal cell carcinoma with a HIF-2 antagonist. Nature. 2016;539:112-7.

58. Cho H, Du X, Rizzi JP, Liberzon E, Chakraborty AA, Gao W, et al. On-target efficacy of a HIF- $2 \alpha$ antagonist in preclinical kidney cancer models. Nature. 2016;539:107-11.

59. Koh MY, Nguyen V, Lemos R, Darnay BG, Kiriakova G, Abdelmelek M, et al. Hypoxia-induced SUMOylation of E3 ligase HAF determines specific activation of HIF2 in clear-cell renal cell carcinoma. Cancer Res. 2015;75:316-29.

60. Chapman G, Liu L, Sahlgren C, Dahlqvist C, Lendahl U. High levels of Notch signaling down-regulate Numb and Numblike. J Cell Biol. 2006;175:535-40.

61. Sahlgren C, Gustafsson MV, Jin S, Poellinger L, Lendahl U. Notch signaling mediates hypoxia-induced tumor cell migration and invasion. Proc Natl Acad Sci USA. 2008;105:6392-7.

62. Kool M, Koster J, Bunt J, Hasselt NE, Lakeman A, van Sluis P, et al. Integrated genomics identifies five medulloblastoma subtypes with distinct genetic profiles, pathway signatures and clinicopathological features. PLoS ONE. 2008;3:1-14. 